Article

\title{
A Two-Stage Decision Framework for Resolving Brownfield Conflicts
}

\author{
Qingye Han ${ }^{1}$, Ginger $\mathrm{Y} . \mathrm{Ke}^{2 * \mathbb{D}}$, Yuming $\mathrm{Zhu}^{3}$ and Hongli $\mathrm{Lin}^{4}$ \\ 1 School of management, Northwestern Polytechnical University, Xi'an, Shannxi, China, 710100; \\ hanqy11@mail.nwpu.edu.cn \\ 2 Faculty of Business Administration, Memorial University of Newfoundland, St. John's, Newfoundland and \\ Labrador, Canada, A1B 3X9; gke@mun.ca \\ 3 School of management, Northwestern Polytechnical University, Xi'an, Shannxi, China, 710100; \\ zym1886@nwpu.edu.cn \\ 4 School of management, Northwestern Polytechnical University, Xi'an, Shannxi, China, 710100; \\ 1hl2016@mail.nwpu.edu.cn \\ * Correspondence: gke@mun.ca; Tel.: +01-709-864-3469
}

\begin{abstract}
Based on the Graph Model of Conflict Resolution (GMCR), a two-stage decision framework is developed to reveal the essence of brownfield incidents and facilitate the resolution of brownfield conflicts caused by the incidents. More particularly, the forward GMCR is utilized in Stage I, the negotiation stage, to simulate the evolution of a brownfield conflict (BC) and predict its potential resolution via stability analysis. If no acceptable equilibrium can be obtained, the $\mathrm{BC}$ progresses into Stage II, the third-party-intervention stage, where the inverse GMCR is used to assist a third party in intervening the conflict to achieve a desirable outcome. To illustrate the practicality of this framework, a recent BC occurred in Changzhou, China, is taken as a case study. Invaluable insights are provided through the computation and investigation of the corresponding preference relationships.
\end{abstract}

Keywords: Graph Model of Conflict Resolution; Brownfields; Inverse problem; Negotiation; Third party intervention

\section{Introduction}

A brownfield generally refers to a property, whose reuse, redevelopment, or expansion may be complicated for the existence or potential existence of pollutants or other hazardous substances [1]. Global industrialization has led to a large quantity of brownfields, which have been exposing high risk to both the human health and environment. It is estimated that the amount of brownfields in the United States is between 0.5 and 1 million [2]. From 2001 to 2015 in China, over 100,000 factories were located elsewhere, which in turn led to about 2 million hectares brownfield in the major cities [3]. What makes it even worse is that more brownfields are being created along with the industrial upgrading process [4]. The reuse of brownfields is a sustainable land use strategy and bring about a wide range of benefits on economy, environment, and society [5,6]. In most industrialized countries, the recreation of brownfields is in a very prior position on their political agendas $[7,8]$. A series of measures, such as relevant legal systems, remediation standards and economic incentives, have been taken into practice.

However, the reuse progress of brownfields is still slow and problematic. A large number of brownfield-related crises on environment, ecology, human health, or even society have been reported. The "Love Canal" disaster, one of the most shocking environmental tragedies in the United States, attracted broad attention for the public health problem caused by the massive dumping of toxic waste on the grounds [9]. A dispute in Elmira, Ontario, Canada, was induced from the aquifer pollution by a chemical plant [10]. The collective poisoning incident of students in Changzhou, which arose from an explosion of second hand pollution during the remediation of brownfields, was reported by the most famous channel (China Central Television, CCTV) in China [11]. These brownfield-related crises have led to numerous and intense conflicts among multiple stakeholders. Generally, these type of incidents 
are sensitive and complicated, easily escalating to severe disputes. A decision framework therefore is in urgently need to support resolving brownfield conflicts.

Three types of analytical tools have been utilized to formally model, predict, and resolve conflicts. The first cluster is the decision making theory. For instance, Maguire and Boiney [12] analyzed an environmental dispute based on decision making tree, and Driscoll et al. [13] used Multi Criteria Decision Making method to resolve management conflicts of future fire. The second group integrates the cost-benefit analysis to support conflict resolution. For example, Gebken and Gibson [14] compared existing dispute resolution methods depending on their transaction cost. Supported by the Utility Theory, Cheung and Suen [15] selected the best dispute resolution strategy, and Zeleznikow et al. [16] built a utility function to help disputes resolution through negotiation. The third and most widely used method is the Game Theory introduced by Von Neumann and Morgenstern [17]. Recent examples include Blokhuis et al. [7], who utilized the classical game theory and conjoint analysis together to predict the government's and redeveloper's choice between conflict and cooperation within the brownfield redevelopment projects; and Glumac et al. [1819], who designed a model to investigate the negotiation process between a developer and a municipality when building the public-private partnership in brownfield redevelopment projects. Under the regime of game theory, the Graph Model of Conflict Resolution (GMCR), first introduced by Fraser and Hipel [20] and then improved and comprehended by Kilgour [21], Thomas [22], Fang et al. [2324], was purposefully proposed to formally resolve real-world disputes. GMCR has several advantages over the classical game theory techniques: requiring much less input information from the user, and allowing decision makers to move in any possible order, which is more realistic in conflict analysis. Due to the benefit of GMCR, our systematic $\mathrm{BC}$ resolution framework is developed on the basis of this methodology.

Researchers have tried to model BC incidents with GMCR. Wang et al. [25] used GMCR to model and analyze the conflict in brownfield redevelopment for forming the strategic perspective of policy making. Hipel et al. [2] developed an negotiation methodology for resolving the brownfield redevelopment issues by providing strategic and tactical management insights. Bashar et al. [26] integrated fuzzy preferences in the GMCR to identify possible solutions of brownfields redevelopment conflicts considering the situation of uncertain preference information. Walker et al. [27] defined a matrix representation of GMCR, which was applied to negotiate the acquisition of a brownfield property from a property owner to a developer. Kuang et al. [28] proposed a grey-based GMCR model to simulate human behaviors in a brownfield redevelopment conflict featuring uncertainty. Wang et al. [29] comprised the ordered weighted averaging, fuzzy real options and GMCR in a framework to facilitate risky project negotiation and a brownfield redevelopment case is used to test the framework. Han et al. [30] examined the financing dilemma of brownfield remediation problems in China with GMCR. Philpot et al. [31] detected new strategic insights for the dispute in Elmira, Ontario using GMCR considering the recent situation in 2016. Yin et al. [32] produced an improved GMCR by integrated a score function and this improved GMCR is applied in the "Changzhou Foreign Language School Incident". Yu and Pei [8] analyzed a case in China by using GMCR with the preference strength taken into account.

Four aspects distinguish this paper with other studies. First, most researchers focused on conflicts in the redevelopment phase of brownfields, while this paper analyzes possible disputes during the whole life cycle of brownfields. Second, the above studies generally only discuss an economy or cooperation issue, whereas this research also addresses the environment and health conflicts induced by brownfields. Third, most research introduced a negotiation model to solve a brownfield dispute without considering the situation that the stakeholders may not be able to resolve it by themselves. But this study designs a two-stage framework where Stage II introduces how a third party can intervene a brownfield conflict and get implications from inverse GMCR analysis. Last but not least, all existing research only used BCs as examples to verify certain improvements of GMCR. The present paper, however, investigates BCs from the viewpoint of the nature of the conflicts, and correspondingly 
proposes a decision framework particularly designed for resolving this type of disputes. In more detail, the objectives of this paper are as follows:

1) designing a framework to systematically support the resolutions of BCs, so to avoid unnecessary conflict escalations;

2) modeling $B C$ to predict the possible outcomes and show the corresponding evolution paths;

3) introducing a third-party-intervention mechanism when the stakeholders of BCs cannot reach acceptable resolutions by themselves;

4) implementing the framework to a collective poisoning incident in China to show the effectiveness.

The rest of this paper is organized as follows. The fundamental theory of GMCR is introduced in Section 2, followed by the presented framework in Section 3. A real brownfield conflict occurred in China is summarized in Section 4 to demonstrate the effectiveness of the framework. Section 4.3 conducts a discussion on how to provide practical implication based on the required preference. Section 5 concludes the present paper and addresses the future research directions.

\section{Methodologies}

\subsection{Graph Model For Conflict Resolution (GMCR)}

The structure of GMCR consists of four main components [23,33].

- A set of stakeholders or decision makers, denoted as $N=\{1,2 \ldots i \ldots n\}$.

- Sets of all decision makers' available options, denoted as $O_{i}=\left\{o_{i 1}, o_{i 2} \ldots\right\}$.

- A set of feasible states, denoted as $S=\left\{s_{1}, s_{2} \ldots s_{m}\right\}$.

- A set of preferences among the above mentioned states, denoted as $P=\left\{P_{i}\right\}$, where $P_{i}$ represents the preferences of decision maker $i$. A couple of binary relations, $\left\{\succ_{i}, \sim_{i}\right\}$, are utilized to express the preferences. For example, $s_{1} \succ_{i} s_{2}$ and $s_{1} \sim_{i} s_{2}$ respectively indicate $s_{1}$ is preferred than $s_{2}$, and $s_{1}$ is indifference with $s_{2}$ for decision maker $i$. It should be noted that the relation of $\succ_{i}$ is asymmetric, while $\sim_{i}$ is symmetric. Because of the transitive characteristic of the two relations, all states can be ordered from the perspective of each decision maker's preferences.

- A directed graph consisted by available moves, denoted as $\left\{M_{i}=\left(S, A_{i}\right)\right\}$, where $A_{i}$ is the set of directed arcs of decision maker $i$. Each arc in the graph represents a move from one state to another adjacent state.

Stability concepts mathematically define the possible stable resolutions of a conflict. GMCR commonly employs four stability concepts, including Nash Stability (Nash) [34], General Metarationality (GMR) [35], Symmetric Metarationality (SMR) [35] and Sequential Stability (SEQ) [36]. The corresponding definitions are given as follows.

- Nash: A state is Nash stable if a decision maker cannot leave it to a preferred one unilaterally.

- GMR: A state is GMR stable if all of a decision maker's unilateral improvements can be sanctioned by other decision makers' subsequent unilateral moves.

- SMR: A state is SMR stable if all of a decision maker's unilateral improvements can still be sanctioned by other decision makers, after a potential response from the main decision maker.

- SEQ: A state is SEQ stable if all of a decision maker's unilateral improvements can be sanctioned by other decision makers.

The characteristics of these stabilities are summarized in Table 1. The "Preference Information" refers to how much information is needed to identify the corresponding stability. For Nash, decision makers only need their own preference information, while all preference information is needed for each decision maker in other three stabilities. The "Foresight" represents the max-count of foreseen moves of a decision maker. Nash checks one move in advance; both GMR and SEQ check two moves in advance; and SMR checks three moves in advance. The "Disimprovement" indicates a decision maker's tendency to move to a relatively less preferred state for purpose of reaching a relatively more 
Table 1. The Characteristics of Stabilities [37,38]

\begin{tabular}{lccc}
\hline Stabilities & Preference Information & Foresight & Disimprovement \\
\hline Nash & Own & Low (1 move) & Never \\
GMR & All & Medium (2 moves) & Sanction only \\
SMR & All & Medium (3 moves) & Sanction only \\
SEQ & All & Medium (2 moves) & Never \\
\hline
\end{tabular}

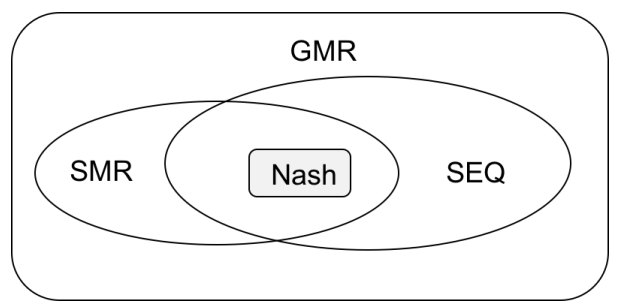

Figure 1. The Relationships of the Four Stabilities

preferred state. No disimprovement is allowed in Nash and SEQ, while sanctions from other decision makers can be disimprovements in GMR and SMR. The relationships of the above mentioned four stabilities can be shown in Figure 1. It should be noted that Nash is the most stable equilibrium because if a state is Nash, all other stabilities hold.

\subsection{Inverse $G M C R$}

The inverse GMCR [39-41] is expended from the above classic GMCR. When the purpose of a user is to model a dispute and predict possible equilibria by the analysis engine, a forward analysis process can be applied. Hence, the classic GMCR is renamed as the forward GMCR here. On the other hand, an inverse GMCR analysis process is more appropriate when the user's perspective is to determine the required preferences to reach a certain desired equilibrium for decision makers. The aforementioned comparison of perspectives is illustrated in Figure2, where a check sign $(\sqrt{ })$ depicts the known information, and a question mark (?) means the corresponding item need to be determined.

A more detailed comparison between the forward and inverse GMCR is summarized in Table 2, in terms of purpose, required preferences, analysis type, output, and sensitivity analysis. Compared to the aim of forward GMCR for predicting the possible equilibria, the inverse GMCR supposes desired equilibria and examine how to reach them from the viewpoint of inverse engineering. A critical feature of inverse GMCR is that it does not require preference information to model the conflict, rather, the preferences are derived from the analysis of desired outcomes. The forward GMCR supports decision making by furnishing possible equilibria, while the inverse GMCR provides required preferences. Furthermore, independent sensitivity analysis, such as status quo analysis and evolution path analysis, is necessary for the forward GMCR; whereas it is integrated by nature for the inverse GMCR.

Table 2. Comparison of Forward and Inverse GMCR

\begin{tabular}{l|l|ll}
\hline \multicolumn{1}{c|}{ Functions } & \multicolumn{1}{|c}{ Forward GMCR } & \multicolumn{3}{|c}{ Inverse GMCR } \\
\hline Purpose & $\begin{array}{l}\text { Predict possible resolutions by } \\
\text { determining equilibria }\end{array}$ & $\begin{array}{l}\text { Support a specific resolution to be } \\
\text { realized }\end{array}$ & No \\
\hline $\begin{array}{l}\text { Required } \\
\text { preferences }\end{array}$ & Full information is required & $\begin{array}{l}\text { Minimal information } \\
\text { information at all }\end{array}$ & / No \\
\hline Analysis type & Static stability analysis & Dynamic analysis & \\
\hline Output & Equilibrium results & $\begin{array}{l}\text { Scenarios and set of possible } \\
\text { preference patterns }\end{array}$ & \\
\hline $\begin{array}{l}\text { Sensitivity } \\
\text { Analysis }\end{array}$ & Must be performed independently & Inherent & \\
\hline
\end{tabular}




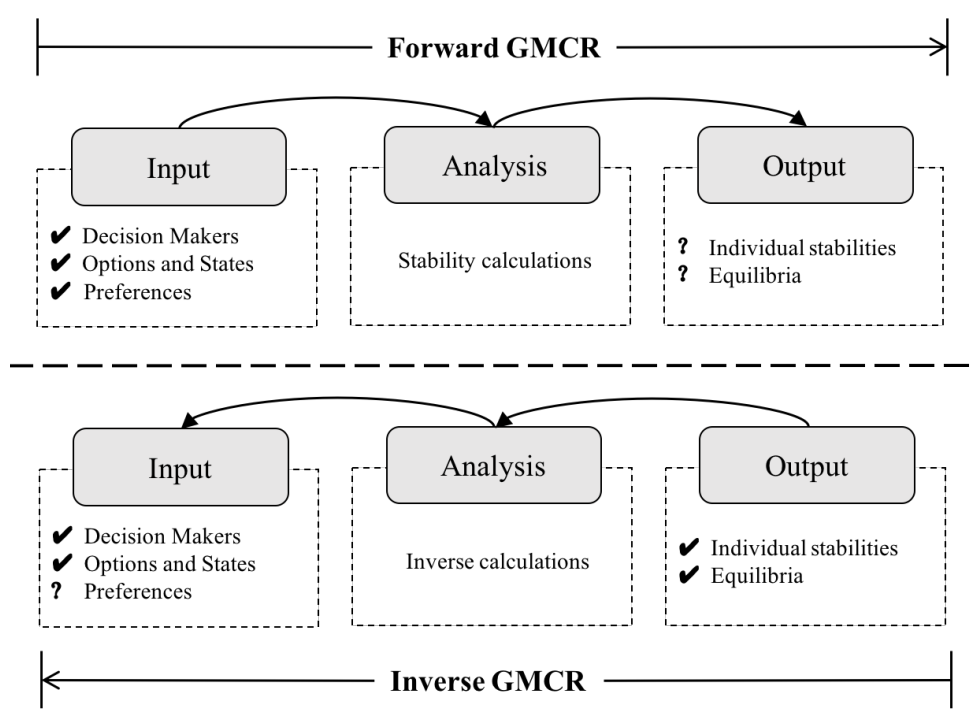

Figure 2. The Logic Comparison of Forward and Inverse GMCR (Adapted from [41,42])

\subsection{Softwares to Supporting the Application of This Method}

Manually solving a problem by using GMCR is possible, yet may be time consuming, error-prone and tiresome [43]. Several Decision Support Systems (DSSs) have been developed to facilitate the utilization of GMCR. The first one is "GMCR I" (1990), which is rarely used because of its unfriendly interface, quite limited maximum states, and plain text results. To overcome these drawbacks, "GMCR II" [44] are designed and known as having a friendly graphical user interface and a powerful analysis engine. The missing of the inverse concept in "GMCR II" leads to the development of "GMCR +" [45], which not only make the DSS easier to use, but also add new extensions, especially the inverse GMCR function. A comparison chart of "GMCR II" and "GMCR +" can be found in Kinsara [43]. The present paper employs the latest "GMCR +" to assist in resolving BCs through the forward and inverse GMCR processes.

\section{A Decision Framework for BC Resolution}

\subsection{Brownfield-Related Disputes and Available Resolutions}

The life cycle of a brownfield can be divided into four phases, namely the idle, remediation, redevelopment, and application (Figure 3). Conflicts may occur in any phase. The main motives for the outbreak of brownfield-related conflicts can be summarized as the health, environment, cooperation, and economy reasons. As indicated in Figure 3, the causes for potential conflicts may differ from each other in different phases. BCs are generally complicated, and even worse, multiple conflicts usually take place simultaneously. Note that the cooperative and economic disputes may only occur during the remediation and redevelopment phases because these two phases usually involve multiple stakeholders, such as owners, municipalities, lenders, redevelopers and purchasers. However, the environmental and healthy conflicts may occur in the entire life cycle, because brownfields remediation is to match the health or environmental risk with the corresponding functionality.

When a brownfield related dispute occurs, measures and counter measures need to be taken by relevant stakeholders. A negotiation process, because of the low cost and straightforward procedure, is usually taken first to reach a possible agreement. However, an acceptable agreement may not be able to be reached, especially in the environmental and healthy disputes due to the associated strong confrontation of interests. In this case, other independent parties, namely the third parties, may be involved to intervene the dispute so to achieve an outcome that is acceptable to all stakeholders. If the $\mathrm{BC}$ still cannot be resolved with the third-party intervention, it inevitably enters into a litigation process, 


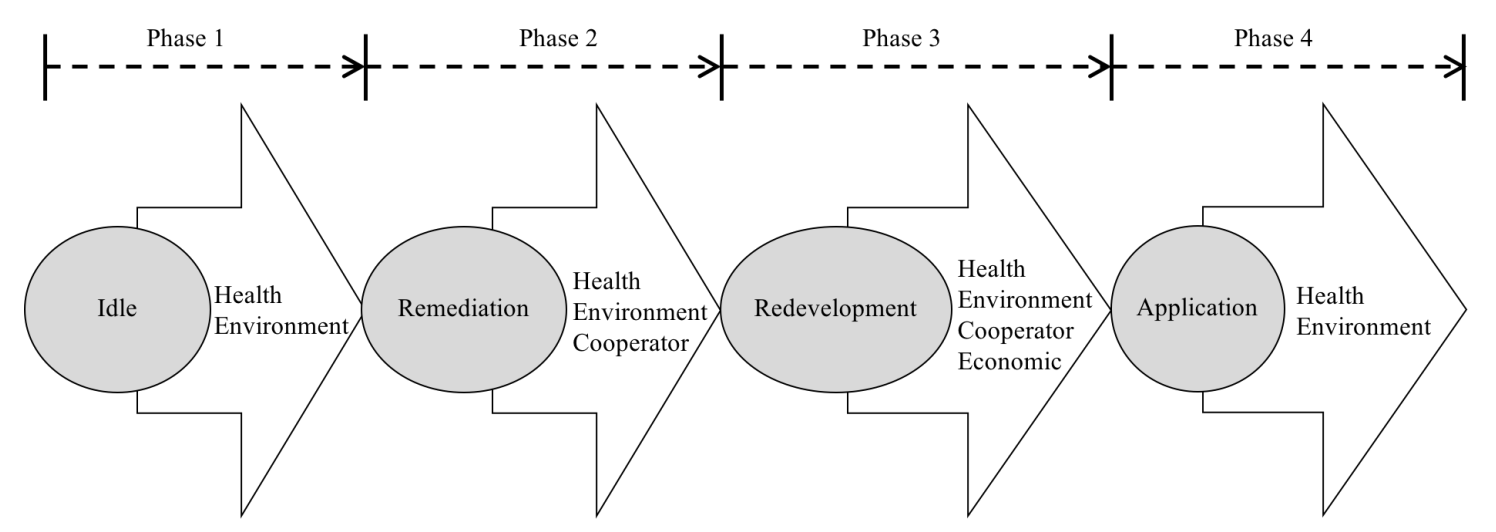

Figure 3. Potential Conflicts in Different Stages of the Entire Life Cycle

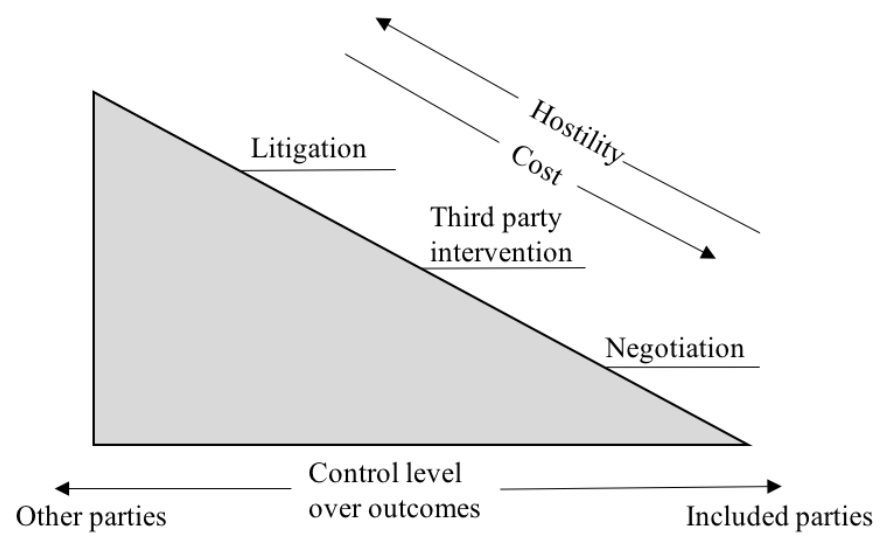

Figure 4. Features of Dispute Resolution Methods (Adapted from [2])

which mandatorily resolve the dispute through lawsuits. Features of the three conflict resolution methods can be seen in Figure 4. Negotiation is the cheapest and most amicable way to resolve a dispute, the third party intervention takes second place, and the litigation is the last. As to the control level over outcomes, the stakeholders take the overall charge in the negotiation, while the litigation process is totally out of the control of the stakeholders. The third party intervention lays between the other two methods.

\subsection{A Two-Stage Decision Making Framework}

Herein, a systematic framework (Figure 5) is introduced to support and facilitate the resolution of BC. As shown, the framework contains two stages, which respectively refer to the negotiation and third-party intervention stages. The major purpose of this framework is to use GMCR as an effective tool applied to the two stages, such that the nature of the dispute can be analyzed and understood in order to seek a reasonable outcome at the first stage, and certain desired resolution(s) can be proposed to practically resolve the conflict at the second stage if no agreement can be achieved in the first stage.

More specifically in this framework, the involving parties communicate with each other to resolve differences and so to reach a consensus at the negotiation stage. The forward GMCR in stage I is used to model the conflict and predict possible equilibria. One or more evolution paths from status quo to the equilibria may also be provided to judge the reachability. The reachable equilibria address information of negotiation results with the highest possibilities, and evolution paths depict how to reach those results. If a reachable and acceptable result exists, the dispute can be resolved by the stakeholders themselves through negotiation. Otherwise, the conflict proceeds into Stage II, where suitable third parties intervene the $\mathrm{BC}$ to assist in achieving a resolution.

In stage II, the inverse GMCR is used to support the third parties to intervene the unresolved dispute proceeded from Stage I. One or more desired equilibria, which can be accepted by all 


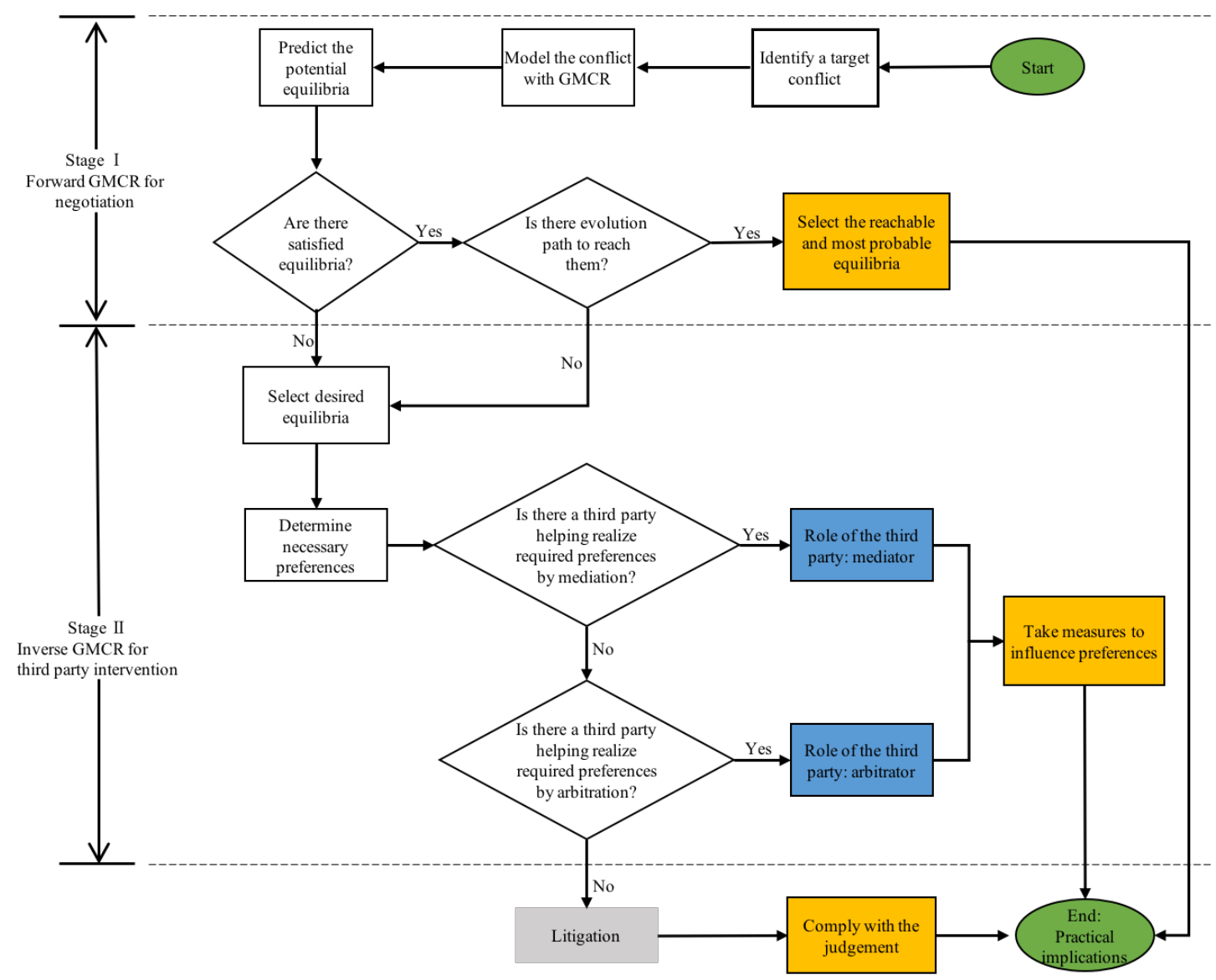

Figure 5. A Decision Making Framework for BC Resolution

stakeholders, are suggested by the third parties. Then, the required and necessary adjustments of preferences for each decision maker can be determined through the inverse GMCR, so to provide the theoretical basis for the third party intervention. Another critical issue in this stage is to identify a suitable third party that is able to induce the preference adjustments. In a specific industry, there may be corresponding organizations and procedures to resolve disputes. For instance, conflict resolution techniques in the construction industry include partnering, dispute review boards, mediation, arbitration, mini-trail, etc. [46]. Some of these techniques, such as the dispute review board, can only be used in the construction industry, while some others, such as mediation and arbitration are commonly used in any industry. In this paper, we pay special attention to these two when a third party intervenes a BC. In more details, when the third party assist in resolving the dispute through the use of specialized communication and facilitation techniques, the party is called a mediator; while the third party acts as an arbitrator if the resolution of the intervention is legally or politically binding on all stakeholders. In general, a mediation is easier to be conducted than an arbitration. Depending on the confrontation degree of $\mathrm{BC}$, the stakeholders determine which approach is more suitable. Potential candidates of the third parties for brownfield-related disputes include environmental non-profit organizations, soil expert teams, government departments, and the arbitral institutions of the court, etc. Among the four parties, the first two are relatively more professional, and the last two are relatively more powerful. If no suitable third party can provide a preferable resolution, the dispute most likely proceeds to a lawsuit.

\section{Case Study}

In this section, a real-world BC occurred in Changzhou, China, is used to illustrate the implementation of the proposed decision framework. The Changzhou Foreign Language School 

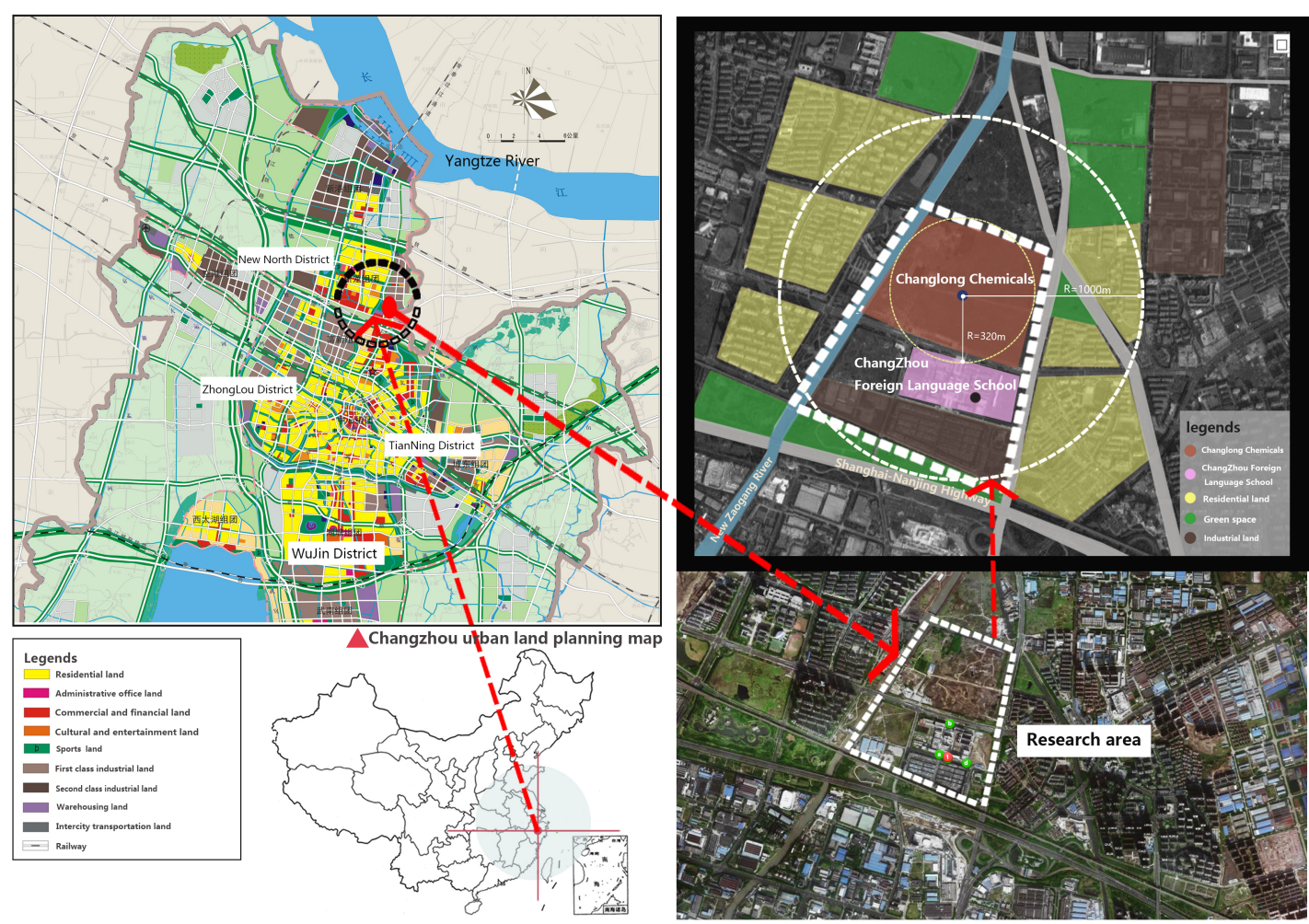

Figure 6. Location of the Research Target (adapted from [48])

(CFLS) is a prestigious high school situated in Changzhou, a southeastern city in China (shown in Figure 6). In December 2015, only three months after moving to a new campus, more than 400 students showed special pathological manifestations. Their parents suspected that the situation was related to the secondary pollution from the nearby ongoing brownfield (the Changlong site) remediation project [47]. The unremitting protest was reported by the China Central Television (generally called CCTV), the official TV channel of China. This incident had attracted widespread attention and led the public to realize the severity of urban land pollution problems. Several months following this toxic incident, the first state-level operable plan for soil management in China, the Action Plan for Prevention and Control of Soil Pollution (the Ministry of Environmental Protection of the People's Republic of China, 2016), was released. The key time points of this incidents are listed in Figure 7.

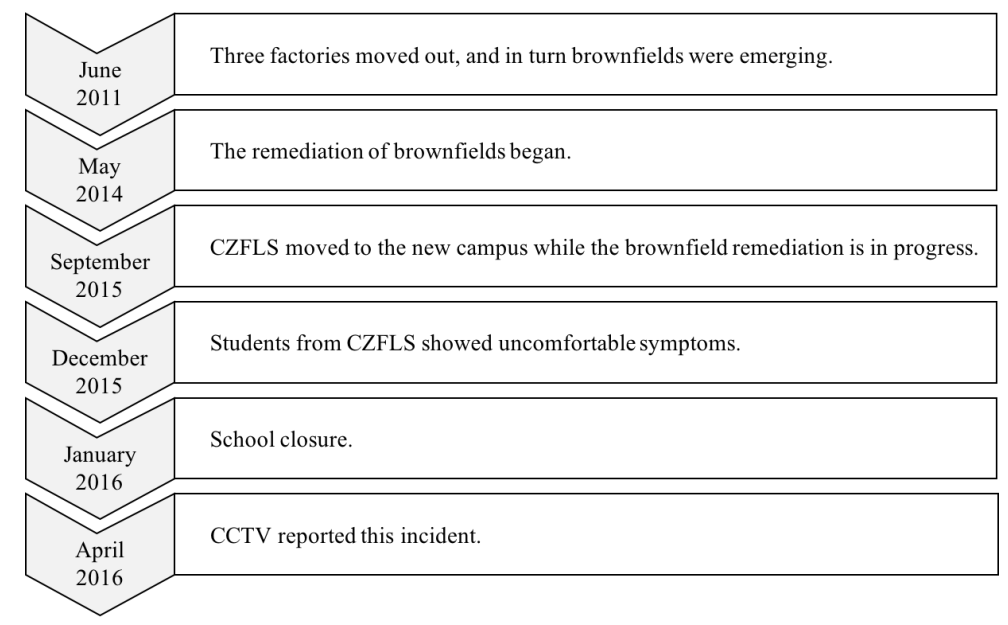

Figure 7. The Course of This Incident 
Table 3. Decision Makers and Their Options

\begin{tabular}{lcl}
\hline $\begin{array}{l}\text { Decision } \\
\text { Makers }\end{array}$ & Options & Descriptions \\
\hline DM 1 & $O_{1}$ & $\begin{array}{l}\text { Take safeguard measures: several available measures may be taken, such as media } \\
\text { exposure, protest, petition and supervision of the remediation process. }\end{array}$ \\
\hline DM 2 & $\mathrm{O}_{2}$ & $\begin{array}{l}\text { Suspend courses in the new campus: shut down the school or change a safe classroom } \\
\text { temporarily until the health risk is eliminated. }\end{array}$ \\
\hline DM 3 & $\mathrm{O}_{3}$ & $\begin{array}{l}\text { Relocate: relocate the new campus to a new safe site. } \\
\text { Punish: punish BPC if it cannot reduce the health risk to an acceptable range. }\end{array}$ \\
\hline DM 4 & $\mathrm{O}_{4}$ & Improve: take measures to improve the current situation. \\
\hline
\end{tabular}

Table 4. Feasible States

\begin{tabular}{llllllllllllllllll}
\hline & & $s_{1}$ & $s_{2}$ & $s_{3}$ & $s_{4}$ & $s_{5}$ & $s_{6}$ & $s_{7}$ & $s_{8}$ & $s_{9}$ & $s_{10}$ & $s_{11}$ & $s_{12}$ & $s_{13}$ & $s_{14}$ & $s_{15}$ & $s_{16}$ \\
\hline DM 1 & 1 & $Y$ & $Y$ & $N$ & $Y$ & $Y$ & $Y$ & $Y$ & $N$ & $Y$ & $Y$ & $N$ & $Y$ & $Y$ & $N$ & $Y$ & $Y$ \\
\hline DM 2 & 2 & $N$ & $Y$ & $N$ & $N$ & $Y$ & $N$ & $Y$ & $N$ & $N$ & $Y$ & $N$ & $N$ & $Y$ & $N$ & $N$ & $Y$ \\
\hline DM 3 & 3 & $N$ & $N$ & $Y$ & $Y$ & $Y$ & $N$ & $N$ & $Y$ & $Y$ & $Y$ & $N$ & $N$ & $N$ & $Y$ & $Y$ & $Y$ \\
& 4 & $N$ & $N$ & $N$ & $N$ & $N$ & $Y$ & $Y$ & $Y$ & $Y$ & $Y$ & $N$ & $N$ & $N$ & $N$ & $N$ & $N$ \\
\hline DM 4 & 5 & $N$ & $N$ & $N$ & $N$ & $N$ & $N$ & $N$ & $N$ & $N$ & $N$ & $Y$ & $Y$ & $Y$ & $Y$ & $Y$ & $Y$ \\
\hline
\end{tabular}

Despite the fact that the event led to multiple disagreements among different parties, we focus on the health conflict because of the corresponding high level of social attention and the complication in achieving an acceptable resolution. The antagonism of interests makes it impossible to resolve the dispute by the negotiations among stakeholders. Therefore, the officers from higher level authority, including Jiangsu province and the central government, were pointed as a third party to intervene this dispute. To show the possibility and effectiveness of the proposed framework, this conflict is modeled in Stage I when it happened. Stage II indicates how the third party induces the dispute to be resolved. In the following subsections, the professional software, "GMCR+" is utilized to demonstrate the implementation of the framework.

\subsection{Stage I: GMCR for negotiation}

Stakeholders of this health conflict consist of students and their parents (DM 1), CFLS (DM 2), Changzhou municipality(DM 3), and the Black Peony Company (BPC), which is responsible for the remediation of the brownfield (DM 4). At this stage, students from CFLS were facing with health risks. As a response, their parents may take a range of measures to protect their children $\left(O_{1}\right)$. In order to ensure the health of the students, the school can suspend courses in the new campus $\left(\mathrm{O}_{2}\right)$. The Changzhou municipality has two options: relocate the school to another safe site so that the health risk can be completely eliminated $\left(\mathrm{O}_{3}\right)$; and request the BPC to improve the status quo, otherwise punish this company $\left(\mathrm{O}_{4}\right)$. BPC may improve the remediation process under the pressure of public opinion $\left(\mathrm{O}_{5}\right)$. These options are explained in Table 3.

For each option, decision makers may select it or not. As a result, the total combination of options, i.e., the number of states, is $32\left(=2^{5}\right)$ results. Note that certain states may be infeasible and therefore should be eliminated. As indicated in Figure 8, three groups of states need to be deleted: (1) DM 4 is punished when it decides to improve the situation ("- - YY"); (2) When DM 1 takes no safeguard measures, DM 2 chooses to suspend courses ("NY---"); and (3) both DM 1 and DM 2 take no measures when DM 3 do not relocate the campus, and DM 4 do not improve the status quo ("NNN - N"). In the above statement, " $Y$ " means the corresponding options being chosen, " $N$ " indicates the corresponding options not being chosen. and "-" represents the option can be either chosen or not. After eliminating infeasible states, "GMCR +" can generate a list including 16 feasible states shown in Table 4.

Figure 9 indicates the irreversible moves of this conflict in "GMCR + ", where double-sided arrows represent reversible moves from an option to another, while the one-way arrows show the only 


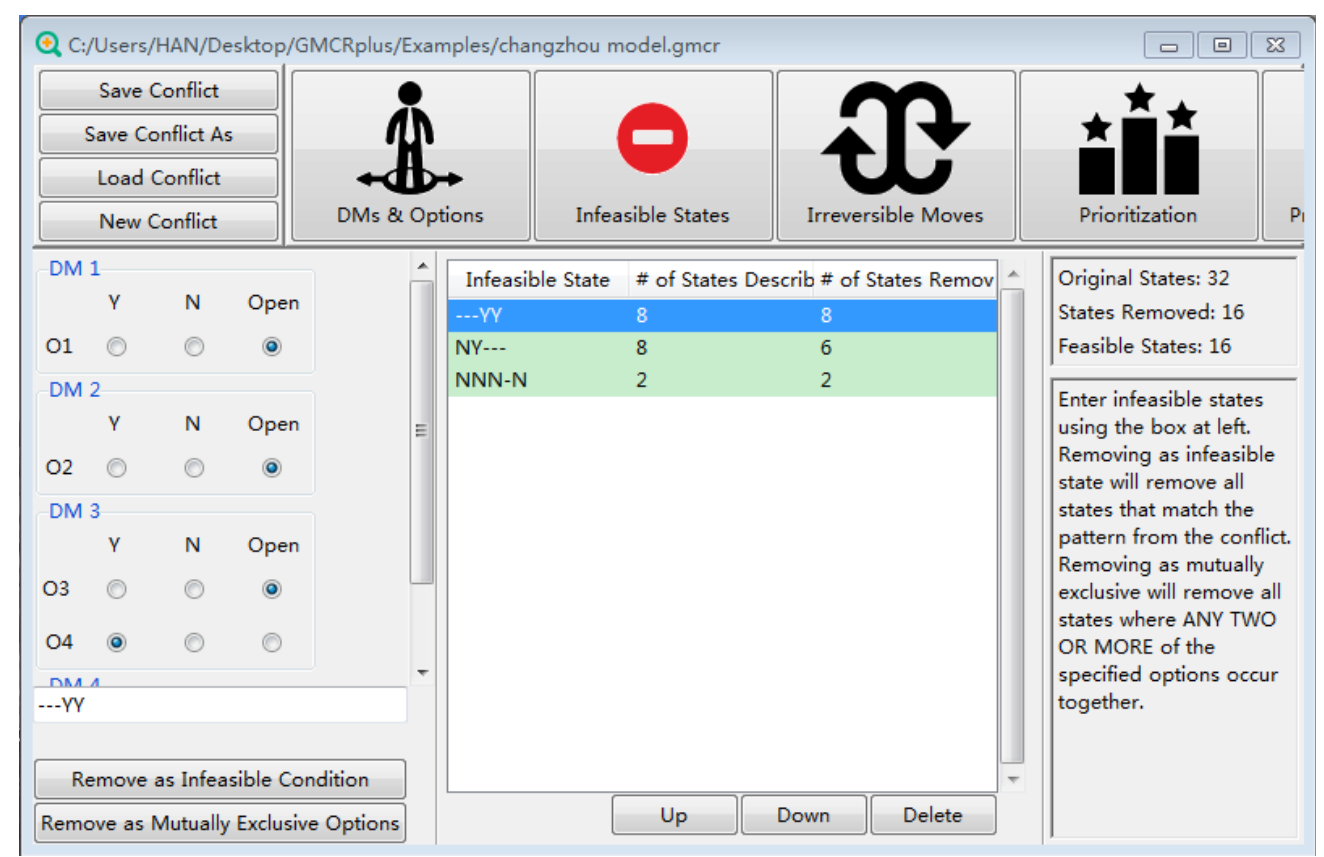

Figure 8. The Process of Removing Infeasible States

direction of moves. For example, DM 3 can only move from not choosing $\mathrm{O}_{3}$ to choosing it, but not vise versa.

In "GMCR+", three techniques, including "Option Prioritizing", "Option Weighting", and "Direct Ranking", can be used to achieve relative preferences of each decision maker. We herein employ the first one for its simplicity and effectiveness. Table 5 illustrates the order of preference prioritization from the most to least for each decision maker. Take the third column (DM 2) for example. DM 2 most prefers the campus can be relocated, and so the highest prioritized option is $\mathrm{O}_{3}$; next DM 2 prefer that the status quo can be improved by BPC $\left(O_{5}\right)$, and followed by $\mathrm{O}_{4}$, where BPC should be punished; then," $2 \operatorname{IF}(-3)$ " means that the courses are suspended $\left(\mathrm{O}_{2}\right)$ if the campus cannot be relocated (not $\mathrm{O}_{3}$ ); and "2IF(-5)" refers to the situation that the courses are suspended $\left(\mathrm{O}_{2}\right)$ if the status cannot be improved by DM 4 (not $\mathrm{O}_{5}$ ). For more detailed algorithm of this ranking process, please check Fang et al. [24]. Based on the information in Table 5, "GMCR+" ranks the feasible states according to each decision maker's preference priority as follows.

- DM 1: $\left(s_{14} \sim_{1} s_{15} \sim_{1} s_{16}\right) \succ_{1}\left(s_{5} \sim_{1} s_{10}\right) \succ_{1}\left(s_{4} \sim_{1} s_{9}\right) \succ_{1}\left(s_{3} \sim_{1} s_{8}\right) \succ_{1} s_{13} \succ_{1} s_{12} \succ_{1} s_{11} \succ_{1}$ $\left(s_{2} \sim_{1} s_{7}\right) \succ_{1}\left(s_{1} \succ_{1} s_{6}\right)$

- DM 2: $\left(s_{16} \sim_{2} s_{15} \sim_{2} s_{14}\right) \succ_{2} s_{10} \succ_{2}\left(s_{9} \sim_{2} s_{8}\right) \succ_{2} s_{5} \succ_{2}\left(s_{4} \sim_{2} s_{3}\right) \succ_{2} s_{13} \succ_{2}\left(s_{12} \sim_{2} s_{11}\right) \succ_{2}$ $s_{7} \succ_{2} s_{6} \succ_{2} s_{2} \succ_{2} s_{1}$

- DM 3: $s_{11} \succ_{3} s_{12} \succ_{3} s_{13} \succ_{3} s_{6} \succ_{3} s_{1} \succ_{3} s_{7} \succ_{3} s_{2} \succ_{3} s_{14} \succ_{3} s_{8} \succ_{3} s_{3} \succ_{3} s_{15} \succ_{3} s_{16} \succ_{3} s_{9} \succ_{3}$ $s_{4} \succ_{3} s_{10} \succ_{3} s_{5}$

- DM 4: $s_{3} \succ_{4} s_{8} \succ_{4} s_{4} \succ_{4} s_{1} \succ_{4} s_{5} \succ_{4} s_{2} \succ_{4} s_{9} \succ_{4} s_{6} \succ_{4} s_{10} \succ_{4} s_{7} \succ_{4} s_{14} \succ_{4} s_{11} \succ_{4} s_{15} \succ_{4} s_{12} \succ_{4}$ $s_{16} \succ_{4} s_{13}$

With the completion of the above steps, the conflict can be modeled in GMCR, and the corresponding integrated graph is shown in Figure 10(a), where arrows depict the moves of decision makers among feasible states. Figure 10(b) is a three-step tree graph beginning from the status quo $\left(s_{1}\right)$. As can be seen, all other states can be achieved in this tree graph, where the dashed arrows represent unilateral improvements.

Figure 11 lists all possible equilibria. As indicated by the check marks, $s_{7}, s_{10}, s_{13}, s_{14}, s_{15}$ and $s_{16}$ are the most stable ones because they satisfy all solution concepts. However, not all equilibria can be achieved in reality. Figure 10(b) can be used to conduct the status quo analysis to present the evolution 


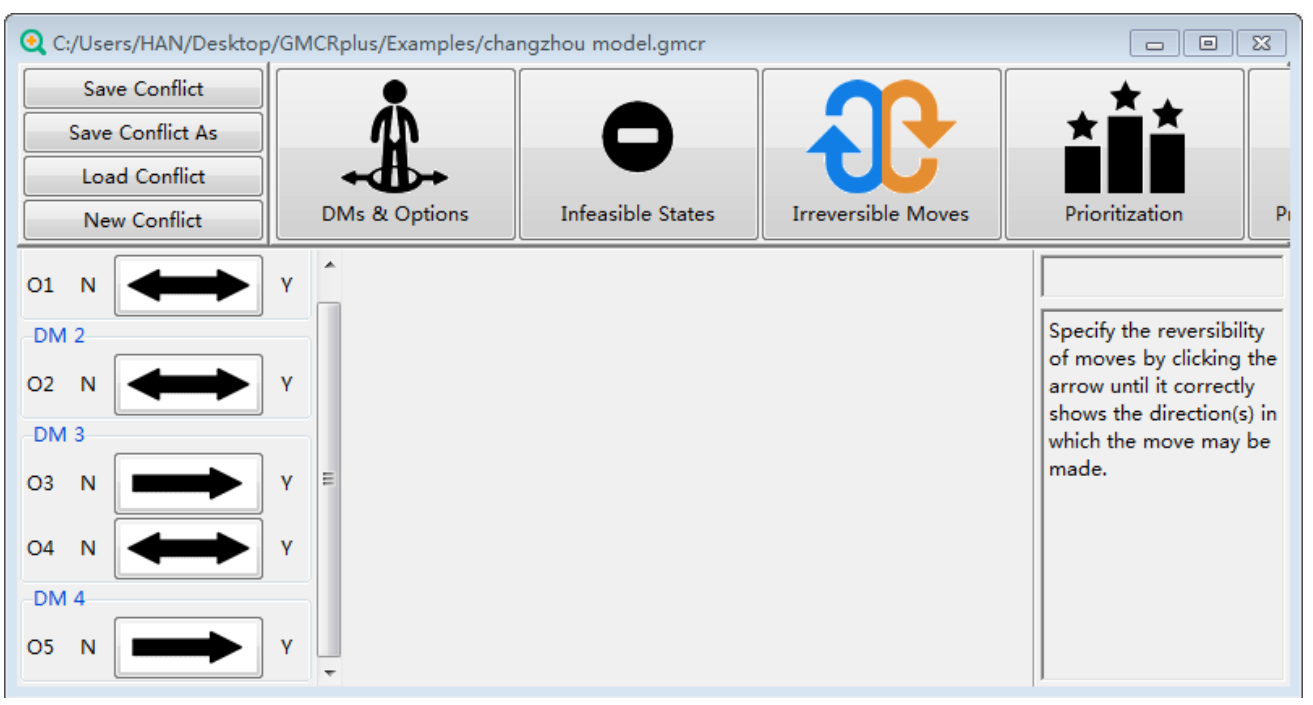

Figure 9. Indication of Irreversible Moves

Table 5. Preferences Statements for Ranking States

\begin{tabular}{lcccc}
\hline Decision Makers & DM 1 & DM 2 & DM3 & DM 4 \\
\hline \multirow{5}{*}{ Preference Statements } & 3 & 3 & -3 & -5 \\
& 5 & 5 & -1 & -1 \\
& $1 \mathrm{IF}(-3)$ & 4 & 5 & -4 \\
& $\operatorname{IIF}(-5)$ & $2 \mathrm{IF}(-3)$ & -2 & -2 \\
& $2 \operatorname{IF}(-3)$ & $2 \mathrm{IF}(-5)$ & 4 & 3 \\
& $2 \operatorname{IF}(-5)$ & & &
\end{tabular}

path from $s_{1}$ to all equilibria. As shown, only $s_{7}$ can be achieved by unilateral improvements, while other equilibria are unreachable.

Although $s_{7}$ is a strong equilibrium, the conflict continues to persist because DM 1 would never accept the fact that DM 4 does not improve the situation, and DM 3 does not relocate the campus. The nonacceptance of $s_{7}$ forces the conflict proceeds to Stage II, where a third party is needed to intervene the conflict.

\subsection{StageII : Inverse GMCR for Third Party Intervention}

In this stage, China's Ministry of Environmental Protection and Jiangsu Provincial Government cooperated to set up a Joint Investigation Team (JIT) to facilitate the resolution of this incident. JIT has more power than any stakeholder of the conflict. Considering the multiple impacts on society, development, environment and economic viability, JIT would prefer that the DM 4 can improve the current situation, so that DM 1 and DM 2 take no actions. Both $s_{11}$ and $s_{14}$ satisfy this condition, while $s_{11}$ is much easier to be reached because of the complexity to relocate a school. Therefore, $s_{11}$ is the most desired outcome of this case.

Thinking from the inverse perspective, to make $s_{11}$ a reachable equilibrium, two conditions must be met: (1) $s_{11}$ satisfies the definition of equilibria; and (2) there is at least one evolution path to reach $s_{11}$ from $s_{1}$. The "Inverse GMCR" at the toolbar of "GMCR+" can help to certain the essential preference profiles. However, it does not show the evolution path to reach the desired equilibrium. As an supplemental function, the "Post Analysis" can help to show the possible paths from the status quo to a desired state. Figure 12 shows how to use this function. On the left side, the "Status Quo" was set as being $s_{1}$, and then $s_{11}$ is taken as "Stable". The third column shows the essential conditions to make $s_{11}$ stable for all decision makers. In this paper, only the Nash stability is considered because it is the most stable one. Two essential conditions to make $s_{11}$ as being a Nash are shown as follows: (I) $s_{11}$ must be more preferred than $s_{12}$ for DM 1 ; and (II) $s_{11}$ must be more preferred than $s_{14}$ for DM 


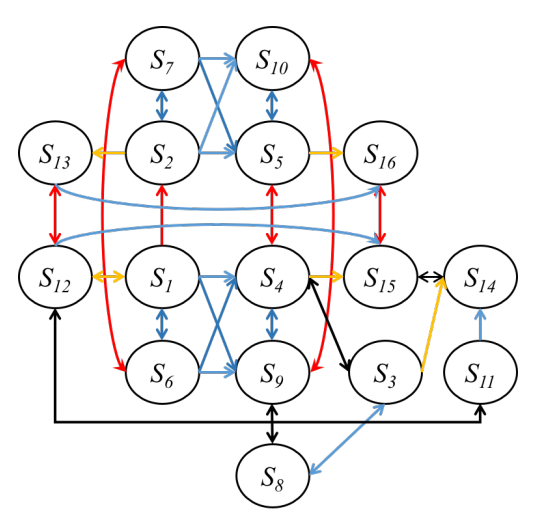

(a)

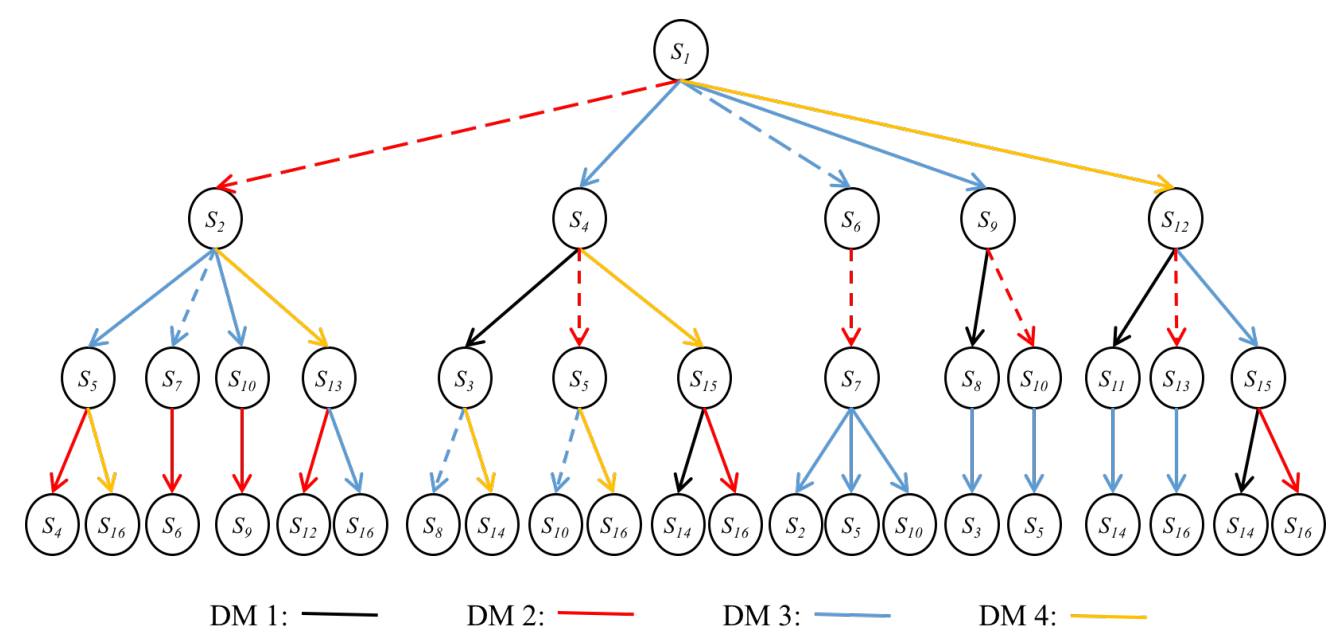

(b)

Figure 10. Graph Model for the Changzhou Conflict

Table 6. Preferences Statements for Ranking States

\begin{tabular}{|c|c|c|c|}
\hline Evolution Paths & Condition $(\mathrm{A})$ & Condition (B) & Descriptions \\
\hline The Top Evolution Path & \multirow{3}{*}{ I, II } & III & \multirow{3}{*}{$\begin{array}{l}\text { I: } s_{11} \succ_{1} s_{12}, \text { II: } s_{11} \succ_{3} s_{14}, \text { III: } s_{12} \succ_{4} s_{1} \text {, } \\
\text { IV: } s_{13} \succ_{4} s_{2}, \text { V: } s_{12} \succ_{2} s_{13} \text {, VI: } s_{7} \succ_{3} s_{2}\end{array}$} \\
\hline The Middle Evolution Path & & IV, V & \\
\hline The Bottom Evolution Path & & IV, V, VI & \\
\hline
\end{tabular}

3. In the second column, each plus sign represents a move, and the green rows show the unilateral improvement considering the original preference order. Figure 13 shows three possible evolution paths, where dash arrows represent the original unilateral moves, and the solid arrows indicate the moves that requires preference adjustments.

\subsection{Discussions of the Intervention Paths}

In this section, we discuss in detail how the required and adjustments of preferences can support the third party to facilitate the resolution of this dispute. Referring back to Figure 13, the three evolution paths can provide valuable strategic insights to help the third party (JIT) resolve the dispute among the stakeholders. More specifically, all the solid arrows in this figure need to be treated by adjusting corresponding preferences. The conditions that need to be met for all paths are summarized in Table 6, where the meaning of all conditions are described in the last column. 


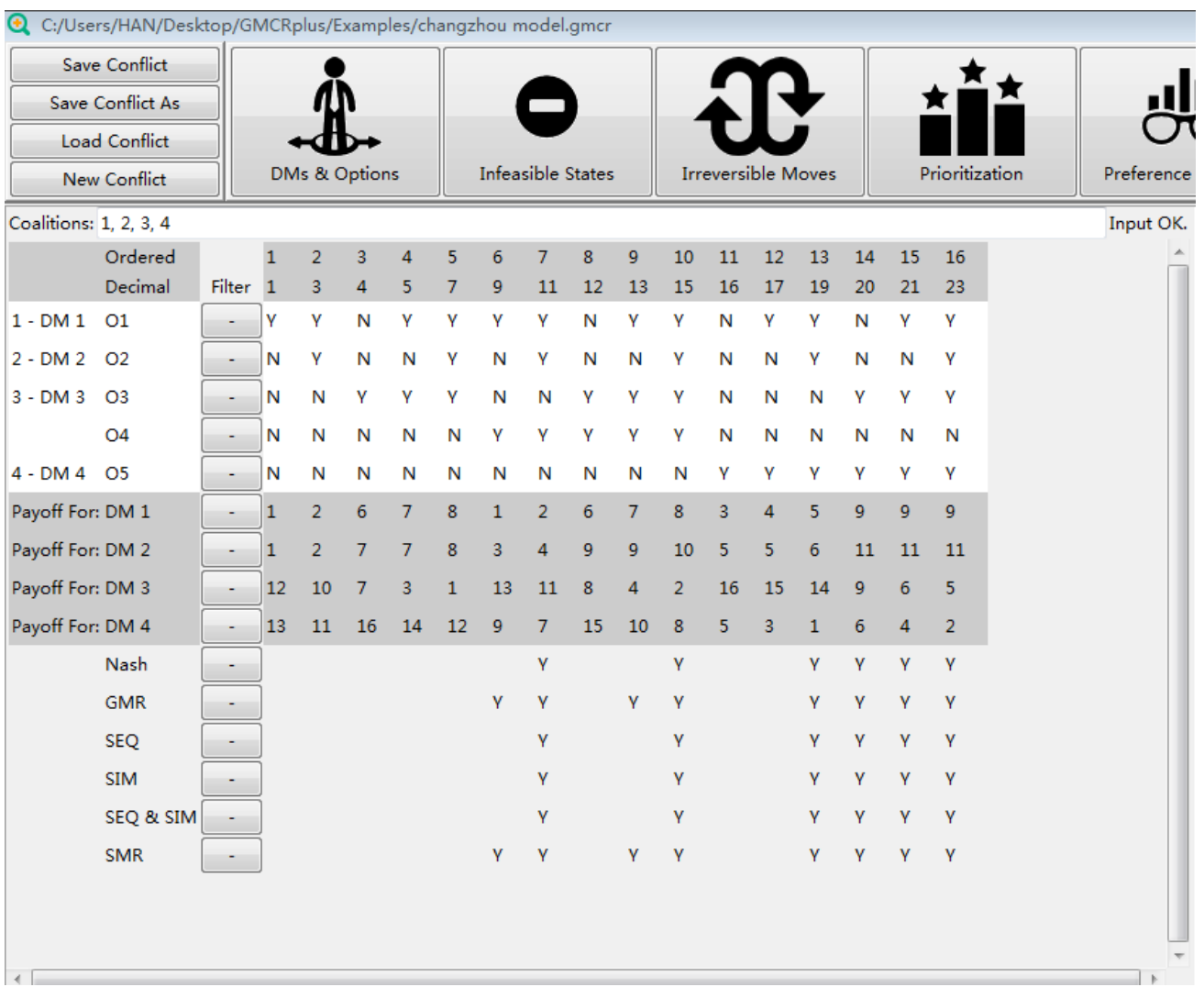

Figure 11. Stability Analysis

\subsubsection{Condition $(\mathrm{A})$}

For all the three paths, conditions I and II must be satisfied as these two conditions are required for Nash. Condition I indicates that $s_{11}$ should be more preferred than $s_{12}$ for DM 1, i.e., when BPC accepts to improve the current situation, students and their parents prefer to give up their resistance, rather than taking certain measures. It is evident that DM 1 chooses to take measures against BPC because DM 1 does not trust that BPC can really improve the situation as promised. To ensure the environmental problem being solved and hence relieve the distrust from DM 1, the third party may set up a special independent monitoring team, which may include experts and also certain number of victim representatives. By doing so, DM 1 can be involved in every step of the remediation process, and therefore would not conduct extra activities.

Condition II represents that $s_{11}$ should be more preferable than $s_{14}$ for DM 3 , in other words, when BPC decides to improve the current situation, the Changzhou community prefers to abandon the relocation option. This condition is the consistent with the original preferences, and so no extra adjustment need to be done.

\subsubsection{Condition (B)}

Next, recommendations for satisfying Condition (B) are discussed in terms of each possible evolution path.

\section{The Top Evolution Path}

If the top evolution path is feasible, condition III ( $s_{12}$ is preferred than $s_{1}$ for DM 4 ) has to be met. That means when students and their parents begin to take safeguard measures, BPC prefers to choose the improvement options. The original remediation plan was to prepare the site for a commercial center, which was extremely time-consuming and required complex processes. But due to the high 


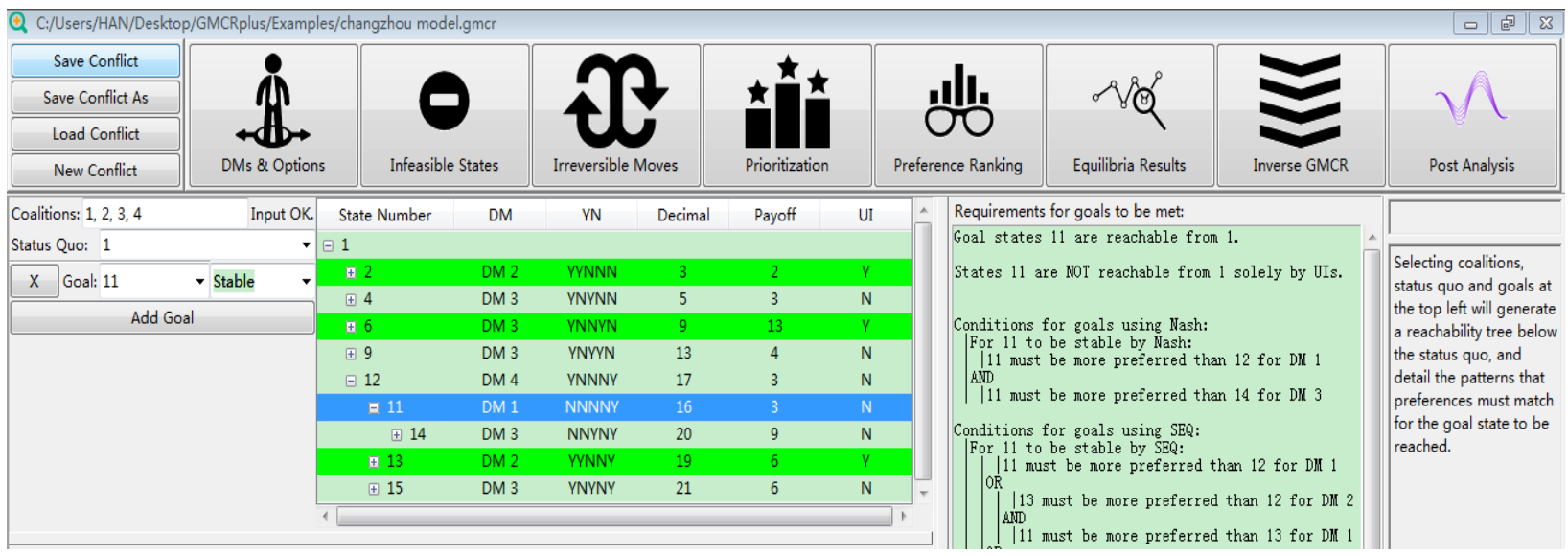

Figure 12. Reachability Test

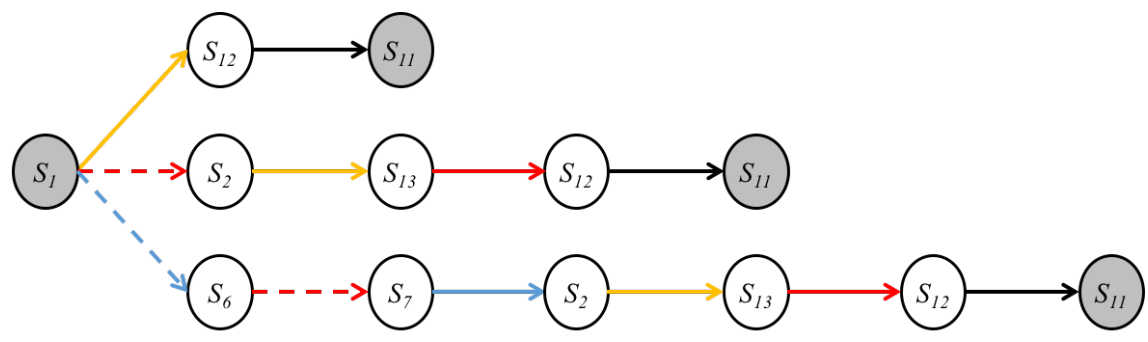

DM 1:

DM 2:

DM 3:

DM 4:

Figure 13. Possible Evolution Paths

negative social impact and high health risk, the original remediation plan may not be able to show the improvement immediately. So JIT may communicate with professional organizations, as well as victims and BPC, and suggest a revised remediation plan. For example, changing the plan from ex-situ remediation to in-situ remediation can substantially cut down the project time, and reduce the possibility of secondary pollution because closed environment is not needed any more. With an agreement among all stakeholders, JIT may be able to persuade DM 4 to adjust its preference and so to satisfy condition III.

Please note that the above recommendation is only for a short-term resolution. For the long run, adding detailed clauses and increasing the level of compensation and punishment in the environmental legal system is the most effective and necessary way.

\section{The Middle Evolution Path}

If the middle evolution path is selected, both condition IV ( $s_{13}$ is preferred than $s_{2}$ for DM 4 ) and condition V ( $s_{12}$ is preferred than $s_{13}$ for DM 2 ) have to be met. In condition IV, BPC should prefer to take improvement option when the students and their parents decide to take safeguard measures, and at the same time, CFLS decides to suspend courses. The analysis of this condition follows the previous condition. In condition V, CFLS prefers to give up suspending courses option when BPC decides to improve, and at the same time, students and their parents do not trust BPC and continue to take safeguard measures. On one hand, the main purpose of suspending courses for CFLS is to call public attentions, so that the surrounding environmental and health risks can be reduced. When students and their parents do not trust BPC's improvement option, CFLS prefers to suspend courses for supporting the safeguard option. On the other hand, CFLS is a famous private high school because of its high rate of university enrollment. The school does not hope to suspend courses for a long time, which may largely impact the teaching schedule. Considering both of the two aspects, it is possible for JIT to influence CFLS to change its preference. First, an independent monitoring team from different 


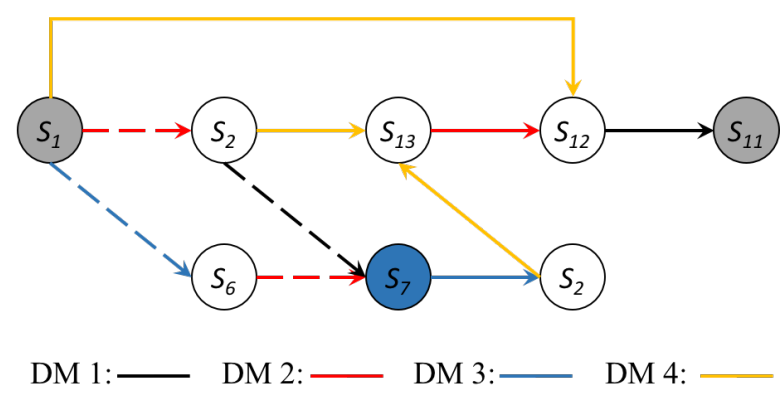

Figure 14. Actual Evolution Paths

sources is essential to increase the trust, so that the students do not resist to attend courses. Second, JIT may guide potential parties (such as CFLS, the parents, the environmental organizations, and even JIT itself) to raise donations for students to purchase water filters and air purifiers. Third, JIT may also provide technique support to CFLS for carrying out long-distance teaching approach.

\section{The Bottom Evolution Path}

If the bottom evolution path is feasible, condition IV, condition V and condition VI ( $s_{7}$ is preferred than $s_{2}$ for DM 3) have to be met. As the first two conditions have been discussed in the previous paragraph, we only consider condition VI here. In this condition, students and their parents take safeguard measures, CFLS suspends courses, and BPC take no improvement option, but Changzhou community do not punish BPC. It is obvious that this situation is impossible to be reached, and thereafter, this evolution path is not feasible.

To sum up, it is possible to reach $s_{11}$ from $s_{1}$ through the top and middle evolution path, while the bottom evolution path is unfeasible because condition VI is hard to exist in practice. It should be noted that the difficulties become greater for JIT, along with the increasing number of preferences that need to be changed.

\subsection{The Validity of Proposed Framework}

Comparing with the actual transition of the conflict further demonstrates the benefit of using the proposed framework. Figure 14 depicts the actual evolution paths of the Changzhou conflict, where the dash arrows indicate the moves in Stage I, and the solid arrows show those of Stage II.

In more details, the conflict started in December 2015, when the students were showing symptoms caused by pollution, and their parents took various measures, hoping to solve the problem immediately. This situation was reflected by state $s_{1}$, which is addressed as the status quo. As the situation progressed, the conflict was stable at state $s_{7}$, where the parents were still taking measures, the school suspended course, and the city municipality chose to punish BPC. Exactly what occurred after the news break-out, this state indicates that the conflict cannot be resolved by the stakeholders themselves through negotiation (Stage I). Particularly, during the 5-month period, the conflict continued to escalate, and even reported by CCTV. It has received widespread concerns from the entire country and induced negative social impact. When the conflict entered Stage II, a third party (JIT) selected state $s_{11}$ as the desired equilibrium, and therefore the bottom path in Figure 12 gives the evolution path at this stage. The analysis in the previous section provides detailed suggestions to the third party in effectively achieving the proposed outcome.

From the above analysis, the influential role of a third party in BCs is clarified. It is evident that our decision framework lays theoretical foundations for the processes of negotiation and third party intervention, which can be used as an extremely helpful tool to resolve brownfield-related conflicts. 


\section{Conclusion}

In recent years, conflicts induced by brownfield incidents occur more frequent, especially in developing countries. Brownfield related conflicts are generally complicated because they may contain economic, health, social, and environmental problems at the same time. A comprehensive method is in urgent need to resolve this type of conflicts. Based on the GMCR theory, a two-stage decision making framework is designed to assist both the stakeholders and the potential third parties in providing invaluable strategic insights, and therefore to enhancing the understanding and providing potential resolutions for brownfield related conflicts. Specifically, the framework is divided into two stages. In Stage I, a forward GMCR model can be built to simulate the moves and counter-moves of stakeholders. By determining the preference relationships of all states for each stakeholder and conducting status quo analysis, the equilibria and evolution paths can be obtained to predict possible resolutions of a brownfield related conflict. In some cases, the predicted equilibria cannot be accepted by certain stakeholders, and then the conflict may enter into a deadlock. The longer the conflict continues, the greater the more negative impact is. To solve this problem, an inverse GMCR model can be constructed in Stage II for potential third parties to intervene a brownfield related conflict. Considering the demands of all stakeholders, a third party should determine one or more states as being desired equilibria. When detecting the requested preference relationships, two aspects should be analyzed: (1) how can a state be an equilibrium? (2) which preferences need to be adjusted on the evolution paths? Based on the obtained information, third parties can take measures to guide the development of a conflict. A recent BC in China, the CFLS toxic incident, is taken as an example to illustrate the effectiveness of the prosed framework. Both forward and inverse analyses are conducted, and several detailed strategies are suggested to facilitate the third party's intervention process.

Author Contributions: Conceptualizatio, methodology, software, validation, formal analysis and investigation, as well as writing, Qingye Han and Ginger Y. Ke; resources and data curation, Qingye Han, Yuming Zhu and Hongli Lin; supervision and project administration, Ginger Y. Ke and Yuming Zhu; funding acquisition, Yuming Zhu; review and approval of the manuscript, all authors.

Funding: This work was sponsored in part by the Provincial Natural Sciences Foundation in Shaanxi, China (Grant No. 2017JM7002) and the Seed Foundation of Innovation and Creation for Graduate Students In Northwestern Polytechnical University (Grant No. ZZ2018038).

Conflicts of Interest: The authors declare no conflict of interest. The funders had no role in the design of the study; in the collection, analyses, or interpretation of data; in the writing of the manuscript, or in the decision to publish the results.

\section{References}

1. Alker, S.; Joy, V.; Roberts, P.; Smith, N. The Definition of Brownfield. Journal of Environmental Planning and Management 2000, 43, 49-69. doi:10.1080/09640560010766.

2. Hipel, K.W.; Hegazy, T.; Yousefi, S. Combined strategic and tactical negotiation methodology for resolving complex brownfield conflicts. Pesquisa Operacional 2010, 30, 281-304.

3. Liu, X. Soil Heavy Metal Pollution and Abatement of China. http://www.mlr.gov.cn/xwdt/jrxw/201510/ t20151029_1385762.htm, 2015. Accessed October 2, 2018.

4. Han, Q.; Zhu, Y.; Ke, G.Y.; Hipel, K.W. An ordinal classification of brownfield remediation projects in China for the allocation of government funding. Land Use Policy 2018, 77, 220-230.

5. Chen, Y.; Hipel, K.W.; Kilgour, D.M.; Zhu, Y. A strategic classification support system for brownfield redevelopment. Environmental Modelling E Software 2009, 24, 647-654.

6. Zhu, Y.; Hipel, K.W.; Ke, G.Y.; Chen, Y. Establishment and optimization of an evaluation index system for brownfield redevelopment projects: An empirical study. Environmental Modelling $\mathcal{E}$ Software 2015, $74,173-182$.

7. Blokhuis, E.; Snijders, C.; Han, Q.; Schaefer, W. Conflicts and cooperation in brownfield redevelopment projects: Application of conjoint analysis and game theory to model strategic decision making. Journal of Urban Planning and Development 2012, 138, 195-205. 
8. Yu, J.; Pei, L.L. Investigation of a Brownfield Conflict Considering the Strength of Preferences. International journal of environmental research and public health 2018, 15, 393.

9. Beck, E.C. The love canal tragedy. Epa Journal 1979, 5, 17-20.

10. Inohara, T.; Hipel, K.W. Coalition analysis in the graph model for conflict resolution. Systems Engineering 2008, 11, 343-359.

11. Liu, C.; Song, W.; Zhou, C. Unsuccessful Urban Governance of Brownfield Land Redevelopment: A Lesson from the Toxic Soil Event in Changzhou, China. Sustainability 2017, 9. doi:10.3390/su9050824.

12. Maguire, L.A.; Boiney, L.G. Resolving Environmental Disputes: a Framework Incorporating Decision Analysis and Dispute Resolution Techniques. Journal of Environmental Management 1994, 42, 31-48. doi:10.1006/jema.1994.1058.

13. Driscoll, D.A.; Bode, M.; Bradstock, R.A.; Keith, D.A.; Penman, T.D.; Price, O.F. Resolving future fire management conflicts using multicriteria decision making. Conservation Biology 2016, 30, $196-205$. doi:10.1111/cobi.12580.

14. Gebken, R.J.; Gibson, G.E. Quantification of Costs for Dispute Resolution Procedures in the Construction Industry. Journal of Professional Issues in Engineering Education and Practice 2006, 132, $264-271$. doi:10.1061/(ASCE)1052-3928(2006)132:3(264).

15. Cheung, S.O.; Suen, H.C.H. A multi-attribute utility model for dispute resolution strategy selection. Construction Management \& Economics 2002, 20, 557-568. doi:10.1080/01446190210157568.

16. Zeleznikow, J.; Bellucci, E.; Schild, U.J.; Mackenzie, G. Bargaining in the shadow of the law: Using utility functions to support legal negotiation. International Conference on Artificial Intelligence and Law, 2007, pp. 237-246. doi:10.1145/1276318.1276365.

17. Von Neumann, J.; Morgenstern, O. Theory of Games and Economic Behavior (1st ed). Princeton: Princeton University Press 1944.

18. Glumac, B.; Han, Q.; Schaefer, W.; van der Krabben, E. Negotiation issues in forming public-private partnerships for brownfield redevelopment: Applying a game theoretical experiment. Land Use Policy 2015, 47, 66-77.

19. Glumac, B.; Han, Q.; Schaefer, W. A negotiation decision model for public-private partnerships in brownfield redevelopment. Environment and Planning B: Urban Analytics and City Science 2018, 45, 145-160.

20. Fraser, N.M.; Hipel, K.W. Solving Complex Conflicts. IEEE Transactions on Systems Man E Cybernetics 1979, 9,805-816.

21. Kilgour, D.M. Equilibria for far-sighted players. Theory \& Decision 1984, 16, 135-157.

22. Thomas, L. Conflict Analysis: Models and Resolutions. Journal of the Operational Research Society 1985, 36, 972-973.

23. Fang, L.; Hipel, K.W.; Kilgour, D.M. Interactive decision making: the graph model for conflict resolution; Vol. 3 , 1993.

24. Fang, L.; Hipel, K.W.; Kilgour, D.M.; Peng, X. A decision support system for interactive decision making-Part II: model formulation. IEEE Transactions On Systems, Man, and Cybernetics, Part C (Applications and Reviews) 2003, 33, 42-55. doi:10.1109/TSMCC.2003.815952.

25. Wang, Q.; Hipel, K.W.; Kilgour, D.M. Conflict analysis in brownfield redevelopment: the erase program in Hamilton, Ontario. Systems, Man and Cybernetics, 2008. SMC 2008. IEEE International Conference on. IEEE, 2008, pp. 2913-2918.

26. Bashar, M.A.; Kilgour, D.M.; Hipel, K.W. Fuzzy preferences in brownfield redevelopment conflicts. Proceeding of Water 2010, p. 8.

27. Walker, S.B.; Hipel, K.W.; Xu, H. A matrix representation of attitudes in conflicts. IEEE Transactions on Systems, Man, and Cybernetics: Systems 2013, 43, 1328-1342.

28. Kuang, H.; Bashar, M.A.; Kilgour, D.M.; Hipel, K.W. Strategic analysis of a brownfield revitalization conflict using the grey-based graph model for conflict resolution. EURO Journal on Decision Processes 2015, 3, 219-248.

29. Wang, Q.; Kilgour, D.M.; Hipel, K.W. Facilitating risky project negotiation: An integrated approach using fuzzy real options, multicriteria analysis, and conflict analysis. Information Sciences 2015, 295, 544-557.

30. Han, Q.; Zhu, Y.; Ke, G.Y. Analyzing the financing dilemma of brownfield remediation in China by using GMCR. Systems, Man, and Cybernetics (SMC), 2016 IEEE International Conference on. IEEE, 2016, pp. 002431-002435. 
31. Philpot, S.L.; Johnson, P.A.; Hipel, K.W. Analysis of a brownfield management conflict in Canada. Hydrological Research Letters 2017, 11, 141-148.

32. Yin, K.; Yu, L.; Li, X. An Improved Graph Model for Conflict Resolution Based on Option Prioritization and Its Application. International journal of environmental research and public health 2017, 14, 1311.

33. Kilgour, D.M.; Hipel, K.W. The graph model for conflict resolution: past, present, and future. Group Decision and Negotiation 2005, 14, 441-460.

34. Nash, J.F.; others. Equilibrium points in n-person games. Proceedings of the national academy of sciences 1950, $36,48-49$.

35. Howard, N. Paradoxes of rationality: games, metagames, and political behavior; MIT press Cambridge, MA, 1971.

36. Fraser, N.M.; Hipel, K.W. Conflict Analysis: Models and Resolutions; Vol. 11, North-Holland, 1984.

37. Hamouda, L.; Kilgour, D.; Hipel, K. Strength of Preference in the Graph Model for Conflict Resolution. Group Decision E Negotiation 2004, 13, 449-462. doi:10.1023/b:grup.0000045751.21207.35.

38. Hu, K.; Hipel, K.W.; Fang, L. A conflict model for the international hazardous waste disposal dispute. Journal of hazardous materials 2009, 172, 138-146.

39. Kinsara, R.A.; Hipel, K.W.; Kilgour, D.M. Inverse approach in third party intervention. Systems, Man, and Cybernetics (SMC), 2013 IEEE International Conference on. IEEE, 2013, pp. 2433-2436.

40. Kinsara, R.A.; Kilgour, D.M.; Hipel, K.W. Inverse approach to the graph model for conflict resolution. IEEE Transactions on Systems, Man, and Cybernetics: Systems 2015, 45, 734-742.

41. Wang, J.; Hipel, K.W.; Fang, L.; Dang, Y. Matrix Representations of the Inverse Problem in the Graph Model for Conflict Resolution. European Journal of Operational Research 2018, 270.

42. Hipel, K.W.; Sakamoto, M.; Hagihara, Y. Third Party Intervention in Conflict Resolution: Dispute Between Bangladesh and India over Control of the Ganges River; 2016. doi:10.1007/978-4-431-55169-0_17.

43. Kinsara, R. Negotiation Support System with Third Party Intervention. PhD thesis, University of Waterloo, 2015.

44. Peng, X. A Decision Support System for Conflict Resolution. PhD thesis, University of Waterloo, 1999.

45. Kinsara, R.A. A Simple Guide to GMCR+. http://www.eng.uwaterloo.ca/ rkinsara/GMCR+Manual.pdf, 2014. Accessed October 2, 2018.

46. Kassab, M.; Hipel, K.; Hegazy, T. Conflict Resolution in Construction Disputes Using the Graph Model. Journal of Construction Engineering and Management 2006, 132, 1043-1052. doi:10.1061/(ASCE)0733-9364(2006)132:10(1043).

47. CCTV. The Pollution Incident in Changzhou foreign Language Scholl. http://tv.cctv.com/2016/04/17/ VIDEWwp1FvGTmvEgIssIvMX9160417.shtml, 2016. Accessed January 3, 2019.

48. Liu, C.; Song, W.; Zhou, C. Unsuccessful Urban Governance of Brownfield Land Redevelopment: A Lesson from the Toxic Soil Event in Changzhou, China. Sustainability 2017, 9, 824. doi:https://doi.org/10.3390/su9050824. 